\title{
NEAT-Lamp and Talking Tree: Beyond Personal Informatics towards Active Workplaces
}

\author{
Fatemeh Moradi * and Mikael Wiberg \\ Department of Informatics, Umeå University, SE-901 87 Umeå, Sweden; mikael.wiberg@umu.se \\ * Correspondence: fatemeh.moradi@umu.se; Tel.: +46-90-7866302
}

Received: 31 October 2017; Accepted: 15 December 2017; Published: 28 December 2017

\begin{abstract}
A growing number of personal informatics (PI) systems have been designed to break the habit of prolonged sitting and to encourage physical activity during workdays and leisure hours. Few studies, however, have investigated the nature of local movement and mobility in workspaces. Relatively little is known about how such movement patterns are shaped and in what ways micro-mobility in workplaces could be increased. By undertaking a concept-driven design approach, and on the basis of our ethnographic prestudy, we introduce a conceptual framework. In this conceptual framework, we indicate the five main agencies that shape local movement and mobility among office workers. On the basis of this empirical and conceptual work, two prototypes, the non-exercise activity thermogenesis (NEAT)-Lamp and Talking Tree, have been designed, implemented and observed in an office environment. This paper describes this design project and articulates the role of discussions in socially established settings in work environments in order to increase daily movement. The paper concludes by highlighting not only technology, but also collective reflections to spark behavioral change in office environments as social settings.
\end{abstract}

Keywords: design; personal informatics; quantified self; workspace; ambient displays

\section{Introduction}

"Personal informatics" (PI) and "quantified self" (QS) are two contemporary notions that foreground interaction design has focused on for a more active way of living our lives. Over the last few years these body- and movement-centered, information-based feedback systems have developed from simple step counters to complex smart watches [1,2]. Many such personal computing systems have been designed, ranging from smartphone applications and wearable sensors to ambient displays, and are now being widely adopted [3-12]. These systems support the creation of an awareness of users' activity levels, helping them to increase their daily movement. Such systems, typically referred to as PI or QS systems, have focused on interaction design aimed at encouraging physical activity and to break sedentary habits in daily life. A handful of such products have recently been made available commercially, including, for example, Fitbit, Nike+, Jawbone and Apple Watch. The way these devices have been designed, constructed and used has focused on providing lots of detailed information to the user from an individual perspective. Investigating various aspects of such PI systems has been the focus of much published literature in recent years [1,2,9,13-17].

However, beyond this first-person/user-centered perspective surrounding the design and use of PI systems, our work suggests that it is important not to neglect the fact that we spend a lot of our time in social settings, not least in work environments. According to the Department of Labor in the United States (http:/ / www.bls.gov/tus/charts/), adults aged 25 to 54 with children spend more than 8 hours per day on work-related activities (see Figure 1). Therefore, for most working adults, time spent stationary and sitting within workspaces contributes most to the overall sitting time in their daily lives [18]. Still, the current PI/QS movement, or at least the design rationale underpinning 
the development of new QS devices and applications, tends not to account for this social aspect of everyday non-activity. Accordingly, our project is an attempt to address this perspective in the design of PI systems, which could help to increase everyday movement in the modern workplace.

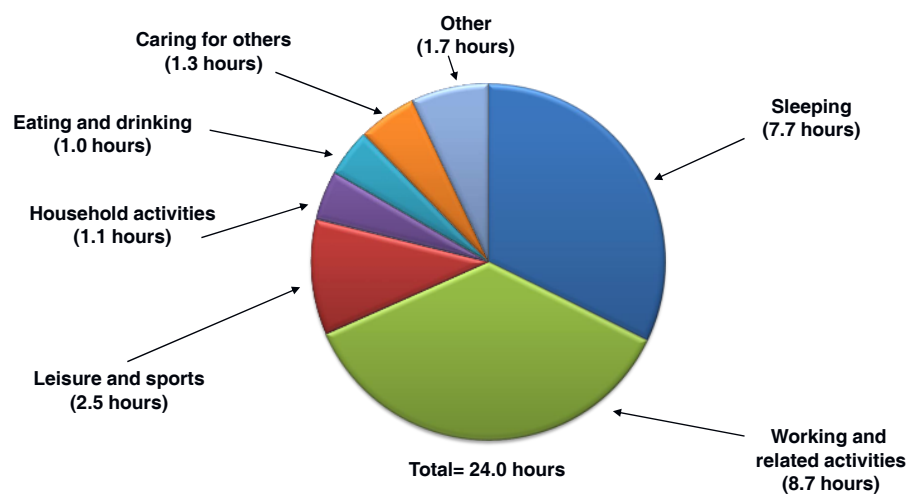

Figure 1. Time spent on work for adults aged 25 to 54. SOURCE: Bureau of Labor Statistics, American Time Use Survey.

\section{How "Stationary Work" Became the Raw Model for Modern Office Workers}

During the Industrial Revolution, along with the great expansion of businesses, designers and technocrats became interested in modifying working practices and redesigning workplaces. Among the different techniques, time and motion studies became very popular $[19,20]$. These methods applied in workspace design sought the most effective combination of workers, machines and the working environment [19-21]. In the search for such effective combinations in workspaces, the designers identified which functions could be performed better by workers and which by machines [20]. Because of the increase in the amount of paperwork in organizations and the growth of office work, time and motion studies were expanded to include productivity with respect to office work. The use of paperwork simplification, office work measurement, and system and procedure analysis are examples of approaches aimed at increasing productivity while decreasing bodily movement. These approaches covered any type of movement, from physical movement in space to micromotion studies of basic hand movements [20,22,23].

Although this trend was not intended to make humans more stationary, it gradually affected how we designed work and workspaces. Stationary work was the side-effect of the modern workplace. In the 1980s and 1990s, with the introduction of computer systems in workplaces, new work layouts were planned [24]. Being influenced by the modernist movement of increasing productivity and optimizing for the elimination of individual movement, these new layouts developed agent-based paradigms for IT design $[25,26]$. New strategies for reaching this goal resulted in having a tool-view of computers, digital agents and assistance and design technology to bridge distances [22]. Gradually in the early 1990s with the introduction of new desktop computers, the computer became ubiquitous not only at work but also in homes. As a result, the majority of us have adopted an inactive lifestyle in which sitting has become our main activity throughout the day. During the last century, the field of ergonomics was invented with the aim of the scientific study of humans at work from a number of perspectives such as psychology, physiology, behavior sciences, and so on [21]. Work management and work analysis were the main objectives of this field to increase performance and reduce disturbance at work [24,27]. However, the inactive lifestyle in workplaces with prolonged sitting hours and stationary work was overlooked at the time.

Increasing Physical Activity (InPhAct) Project is our five-year transdisciplinary research project that was launched in the fall of 2012 and is aimed at investigating ways to break the habit of prolonged sitting in offices and encouraging physical activity in workspaces. Today, our research project involves researchers from the Department of Informatics and the Department of Public Health and Clinical 
Medicine of Umeå University as well as the Umeå Institute of Design. During this project, we conducted two ethnographic studies lasting more than 5 months in two office spaces in order to understand local movement and mobility patterns in contemporary office spaces $[28,29]$. In these two field studies, a considerable amount of data was systematically gathered in the form of sketches (see Figures 2 and 5), field notes, and photographs (Figures 6 and 9) and through informal and semi-structured interviews. On the basis of these ethnographic observations, we have concluded that movement and mobility, as essential social practices in modern workspaces, are shaped by five different categories of agency. In this paper, we present a framework that describes these agencies, and we present two design projects conducted with a point of departure in this conceptual work and our empirical, ethnographic material.

Yet a third important point of departure for our project has been our fundamental viewpoint that local movement and mobility are not only an individual phenomenon, but are also a social aspect of work; in fact, mobility is essential for collaboration in office settings [30,31], and mobility is an effect of social collaboration. Accordingly, designs for increased physical activity should consider the existing movement patterns in workspaces. This paper contributes to a deeper understanding of local movement with work environments with the use of our proposed conceptual framework. Furthermore, it reveals how this framework could assist in the design and analysis of prototypes for increasing local movement in workspaces.

\section{Background and Related Work}

As a result of an inactive lifestyle, the incidence of overweight individuals and obesity is becoming a major problem worldwide. According to a number of recently conducted medical studies, prolonged sitting increases the risk of causes of mortality, including cardiovascular disease (CVD), certain types of cancer, and non-CVD/noncancer mortality in adults [32-37]. Prolonged sitting covers all types of sedentary behavior, including sitting or lying down in all situations associated with working, eating and traveling that incur no more than 1.5 metabolic equivalents [22,37].

In recent years, it has become apparent that regular physical activity within the context of everyday practices yields health benefits [33,38]. Existing research indicates that non-exercise activity thermogenesis (NEAT), which refers to any physical activity other than sport-type exercise, including work-related activities, has a direct effect on the physiology of weight change $[32,33]$.

As discussed above, there have been a variety of PI design projects conducted with the focus of encouraging movement in everyday life. In the field of public health, there have also been a number of attempts in modifying workplaces for increasing physical activity [18,32-39]. Introducing treadmills in offices as a tool to shift from sitting to standing deskwork and increase NEAT is among the most recent attempts for designing active workplaces [34]. Although the solution is considered an effective way to make changes in this environment, efficient and silent treadmills are still expensive and require substantial space [35]. Therefore, alternative approaches, such as game-based mobile applications designed to increase NEAT, have recently been explored [32]. Others have suggested computer break programs for interrupting sedentary office work. One example is "Booster Break" - an organized short exercise routine that is designed to interrupt prolonged siting with the aim to improve physical and psychological health $[9,36,39]$.

Creating awareness of problems associated with sitting still for prolonged periods in workspaces has also been the focus of various QS- and PI-related designs in different formats-ranging from mobile applications to ambient displays [3-8,10-12]. The QS movement deals with the individual engagement of self-tracking of any kind in order to obtain QS knowledge and act on it $[1,2,17]$. Standard contemporary QS devices that focus on increasing movement include, for example, Fitbit, Nike+ and Jawbone Up fitness trackers. Quantitative data collection is the first step towards generating meaningful insights for action-taking results $[17,40]$. Similarly, PI systems refer to software and hardware that collect data based on the user's behavior, and these aim to create reflection with the proper visualization of data. As Li et al. [14] describes, these systems function in a stage-based model from preparation to collection and integration in order to provide reflection, which finally results in appropriate action. There are 
handful of research projects that focus on motivating physical activities with the use of a combination of collection and reflection on PI $[1,14,16]$. Houston is one of the early mobile prototype applications that encourages physical activity by sharing steps with others [13]. Other designs such as Fish'n'Steps [12], UbiFit Garden [5], StepMatron [8], Shakra [3] and Body-Bugg [12] are similar applications that deal with motivating users to increase their physical activities.

Further, visual representation has been considered as an important aspect of PI tools for reflection [14]. Most physical activity tracking technologies use charts to represent quantified data. One of the challenges ahead of the QS movement is that users are readily interacting with large streams of data but tools for meaning-making are lacking [2]. As humans, we are more capable of effectively thinking in stories rather than numbers [17]; therefore some of the QS devices include both dimensions of quantitative and qualitative data representation. In other words, there is an opportunity for making devices that think in terms of story narratives rather than statistics [2]. Ubicomp researchers have attempted to explore visualizations in the form of living metaphors or informative art displays using abstract art as a way of creating reflection [41]. It has also been suggested that it would be valuable to design ambient displays with low complexity and a low-engagement interface to encourage physical activity [4]. A recent example of such an interface is Apple Watch's design, showing the level of activity. In fact, PI focuses on collecting data for the purpose of gaining self-knowledge through reflection [16]; therefore the process of reflection could be considered to be the main concept behind the design of any PI system. More importantly, reflection could be viewed as a learning tool that requires skills such as self-awareness, critical analysis, synthesis and evaluation [16].

As a result, a variety of designs and studies have focused on the use of peripheral or ambient displays for providing reflection on the level of physical activity $[6,7,10,11]$. Ambient displays refer to technologies that can provide useful information while blending smoothly into the surrounding environment and that have the ability to move the information from the periphery to the center of human attention and back again $[7,10]$. The concept of ambient displays originates from the design of calm technologies, with the initial example of Mark Weiser's The Dangling String [42]. This design has the advantage of conveying information regarding network traffic in an office in a subtle matter [10,42]. As Weiser proposes, this technology engages with both the center and periphery of our attention and moves back and forth between the two [42], thus helping us to increase knowledge and ability without causing information overload. The ambiguous nature of use in these displays creates an agenda for technologies aimed at reflection and moments of mental rest rather than efficiency in performance [43]. Such designs could aid their users in discussion and open-ended sense-making processes [1].

\section{Design Rational}

If reflection in the context of designing PI is ultimately about conceptually crafting how the information feedback system is mirrored, then there is a need for a method supporting this conceptualization.

On the other hand, our aim in this project was to develop prototypes that aid users in discussion and open-ended sense-making around everyday movements. Therefore, the primarily objective of our study was to develop an understanding of local movement and mobility in office spaces. Here, a 5 month ethnographic observation was our first empirical attempt. As it is challenging to generate design rationales based on empirical study, we used a design-driven approach to develop concepts. With the framework established with the help of the design-driven approach from our ethnographic study, we addressed the true activity in workplaces and added a vocabulary for defining local movement and mobility in workspaces. In the end, the design of both of our prototypes, the NEAT-Lamp and Talking Tree, was inspired by our empirical studies with a concept-driven design approach [44].

\subsection{Concept-Driven Design Approach}

In our project, we used concept-driven design methods as a foundation for advancing PI design [44]. In concept-driven research, the focus is on knowledge production in the form of theoretical 
or conceptual development. It involves an exploratory investigation of established theories with the overall aim of improving and widening the range of theory and knowledge. Overall in this type of research, there is a deliberate intention to theorize about the nature of interaction. The concept of the design becomes a carrier of knowledge but also establishes a conceptual framework and challenge for future design work [44]. The idea is to think about all invisible qualities to reveal the core quality in the concept of the design. The key of a conceptual design is to manifest all the combined knowledge that will influence the design so that the knowledge is embodied in the artifact [44]. In a similar approach, Höök and Löwgren [45] introduced the notion of a strong concept, which is generative and also carries the core design idea. They claim that strong concepts are design elements but at the same time are a part of the artifact.

In order to arrive at a well-grounded conceptual framework, we have conducted two extensive ethnographic studies lasting for more than 5 months in two different office-based workspaces (two different companies). During the ethnographic prestudies, we gathered field notes and sketches of local movement and mobility in the office layout (see Figure 2). Ethnographic studies have been considered as a common approach in the fields of HCI (Human Computer Interaction) and CSCW (Computer Supported Collaborative Work) $[28,29,46]$. There has in fact been a wide range of ethnographic studies conducted in workplaces with a specific focus on collaboration or efficiency $[30,31]$. However during the last two decades of the 20th century, with the introduction of information and communication technologies, the concept of mobility has expanded and transformed [47]. Limited numbers of studies have focused on local movement and mobility in workspaces in order to increase collaboration [30,31]. Mobility is considered essential for the use of shared resources and communication [30]. While conducting our ethnographic studies, we very soon realized the need for local movement and mobility as social practices in workspaces (see Figure 2). In fact, office workers are mobile during work hours, and movement is constantly shaped and reshaped.

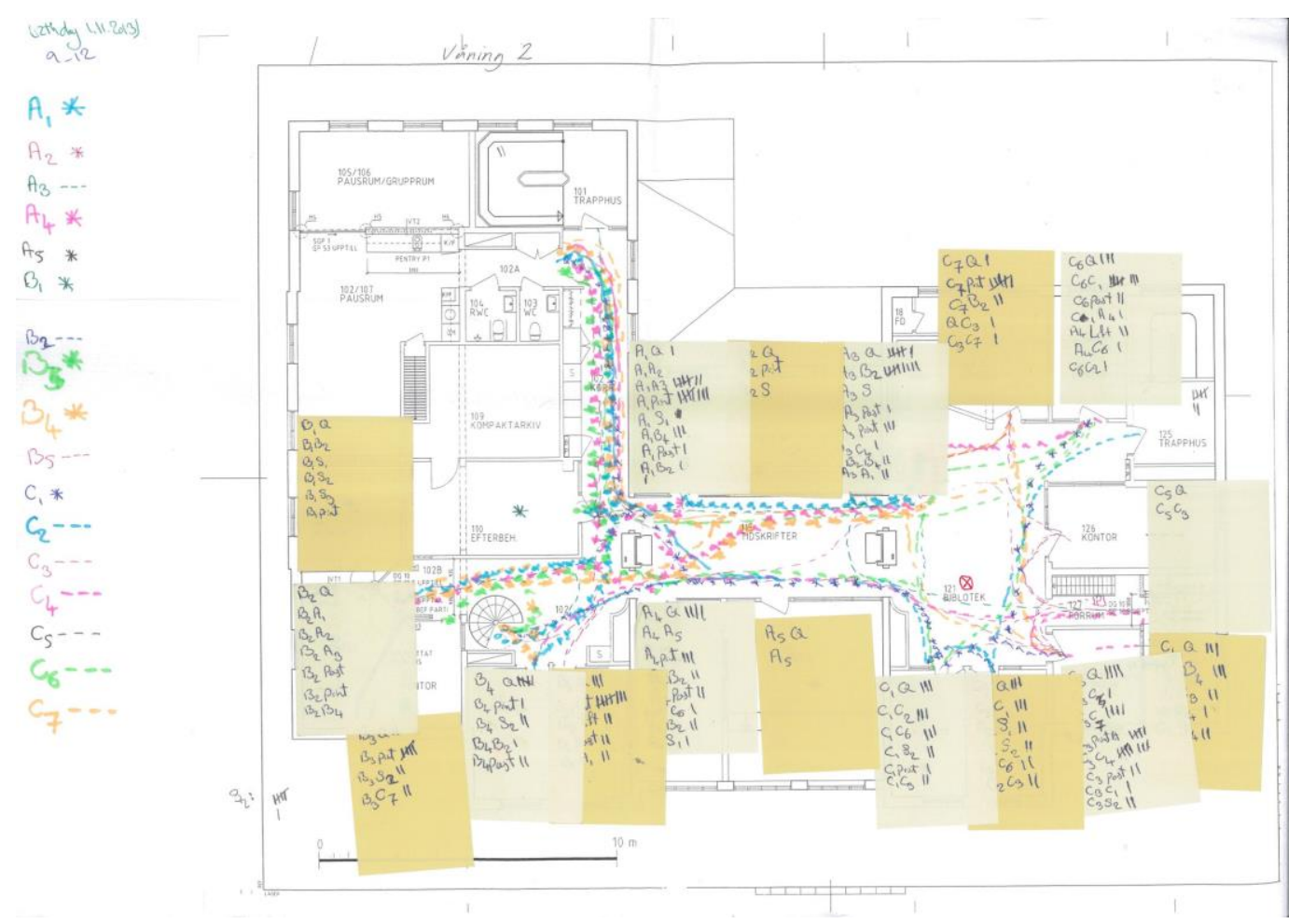

Figure 2. An example of how we took field notes of local mobility in the workplace during one of our ethnographic studies. 


\subsection{Conceptual Framework}

On the basis of our ethnographic work, we have developed a conceptual framework that identifies five categories of agency that are influential in shaping patterns of local movement and mobility in workspaces (see Figure 3). The process behind the development of this framework consisted of the thematic analysis of the field notes and informal interview transcripts gathered in our observational ethnographic study. The process of data collection as well as the coding was conducted by one of the authors. Initially, the field notes from the study were carefully coded to more than 1200 open codes. These 1200 codes were clustered into five categories. This framework provided us with a deeper understanding of the existing mobility pattern in workspaces. This understanding of the current movement in offices is important for designing novel PI systems for increasing physical activity among office workers. The five categories are as follows.

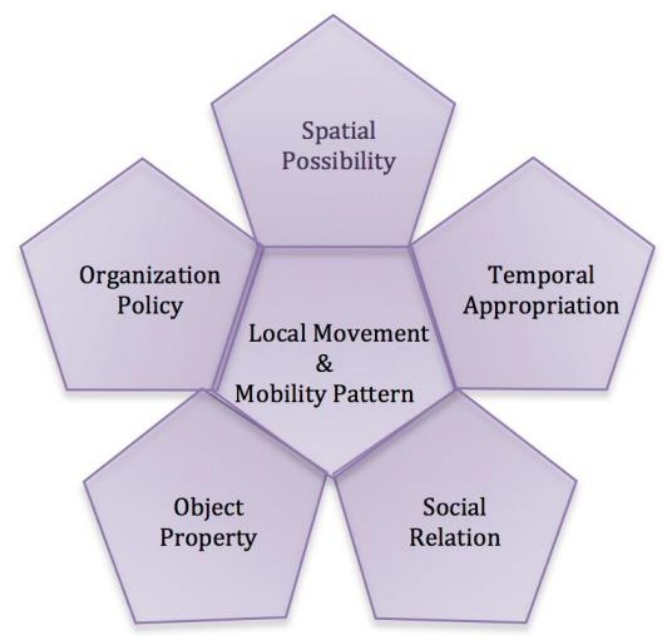

Figure 3. The conceptual framework.

Spatial Possibility refers to the possibilities that the architectural space offers for certain movements. As an example, depending on where a staircase is located in a building, the movement patterns of the office workers will be altered. The same applies to the interior design of the office spaces. However, this agency is not limited to physical spaces and could also refer to social spaces created for different activities such as talking or taking an exercise break.

Temporal Appropriation is a term referring to particular movements and mobility within the office space tied to a specific point in time. Time in this definition could relate to a specific hour for conducting meetings, exercise breaks or lunch breaks. It could also refer to a day of the week, or a specific week in the month, such as the delivery week.

Social Relation is linked to the social network that is created by office workers in workspaces. These social networks are formed as a result of work responsibilities, in which office workers depend on one another for the completion of a task, for example, individuals who work in the same department. However personal social networks are also visible in workspaces: some office workers establish friendships and form personal relationships.

Object Property characterizes a quality within objects in the workspace that require physical movement towards them for interaction. A simple example would be a printer that requires office workers to walk up to it to collect their printing. In each workspace, there are a number of such objects, equipment or devices, such as coffee machines, white boards and technical equipment.

Organization Policy relating to movement and physical activity of the office workers has an influence on the daily mobility patterns in the workspace. As an example, an organization that encourages their office workers to take exercise breaks twice a day fosters physical movement in the 
setting. Other polices could include equipping offices with adjustable desks, short walks during lunch hours, or walking meetings.

As stated previously, these five categories of agency are influential in shaping the movement and mobility patterns in a workspace. By spending time in office spaces in order to understand movement therein, these agencies could easily be elucidated. The aim of this conceptual framework is to bring these agencies to our attention while conceptualizing the prototypes as a challenge for future design work.

\section{The Design Work}

As noted, the concept of design becomes the carrier of knowledge and establishes a conceptual framework. Our framework created challenges for future design work, resulting in the creation of two prototypes [44]. Designing to increase physical activity in workspaces requires attention and delicacy in order to avoid any disturbance in the flow of work. Reflecting mobility patterns in a digitalized way through ambient displays could be considered to be one solution to this. Because these designs can be tuned out, they could be considered a possible solution to the threat of information overload [10]. Moreover, the information from the design can inherently shift to the background when the office workers need to focus on other matters. Given the fact that our method in this study was observational ethnography, fixed and strict planning generally was avoided. Our method was conducted in reality and by observing the practices; on the basis of what we observed, we designed our prototypes. We would like to strongly state that we had no knowledge prior to our study on what or how many prototypes we would design and evaluate.

After conducting several brainstorming meetings during the InPhAct Project and discussing the challenges ahead for designing a PI system based on our framework, we came up with two prototypes. Our first prototype, the NEAT-Lamp, is the outcome of our first observational ethnographic study, and similarly, the Talking Tree is the outcome of the second observational ethnographic study. The aim behind the design of these two prototypes was to see how they foster local movement and mobility in workspaces and how the five agencies come into play with these designs. In the following, we describe, in detail, the design rationale behind each and illustrate our observations on how these designs created discussions and moments of reflection on movement and physical activity among office workers. We also describe how these discussions resulted in changes that fostered worker movement during work hours.

\subsection{NEAT Lamp}

The NEAT-Lamp is a simple sensor-based lamp that is connected to a computer via a USB connector (see Figure 4). The lamp is placed on the table in front of the office worker and turns on after $25 \mathrm{~min}$ as a reminder that the worker has been stationary during this time. Proximity sensors have been utilized in this design for this matter. The lamp will automatically turn off as soon as the office worker leaves his/her current position. The idea behind the design of this prototype was inspired by the agency of object property within our framework. The goal was to create an object that had the property of fostering movement in the workspace and also created a reminder outside a computer screen or mobile phone. While designing this artifact, we had in mind that the NEAT-Lamp should not create any disturbance to the work process. Therefore, the design deliberately blends in with the environment, and the color of the light is green so that, combined with the patterns on the shade, it would create the sense of a living plant, which is a common object in workspaces. 


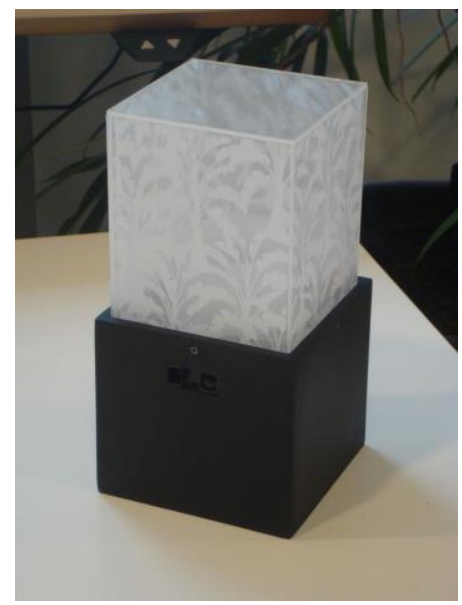

Figure 4. Non-exercise activity thermogenesis (NEAT)-Lamp.

\subsubsection{Placing and Observation}

After conducting a short pilot study using the NEAT-Lamp, this prototype was introduced to an open-plan workspace. Before installing this gadget, a 3 week ethnographic observation was undertaken in the setting. The aim of this investigation was to become familiar with the workspace and observe how the five agencies in the framework shaped the movement and mobility patterns therein. Moreover, this study was essential in order to figure out how our prototype altered movement and mobility patterns in the workspace. The workplace comprised an open space with cubical offices. The office workers were mostly electrical engineers, mechanical engineers and a software designer working in a test and design department. The five agencies of the framework soon became visible. It was clear that the workers were aware of the problems associated with prolonged sitting, and they had experienced the use of step counters in a competition a year prior to our study. Moreover, a group of them undertook exercise breaks twice a day, an activity promoted by their organization. Furthermore, they were encouraged to take a walk during the lunch hour (see Figure 5).

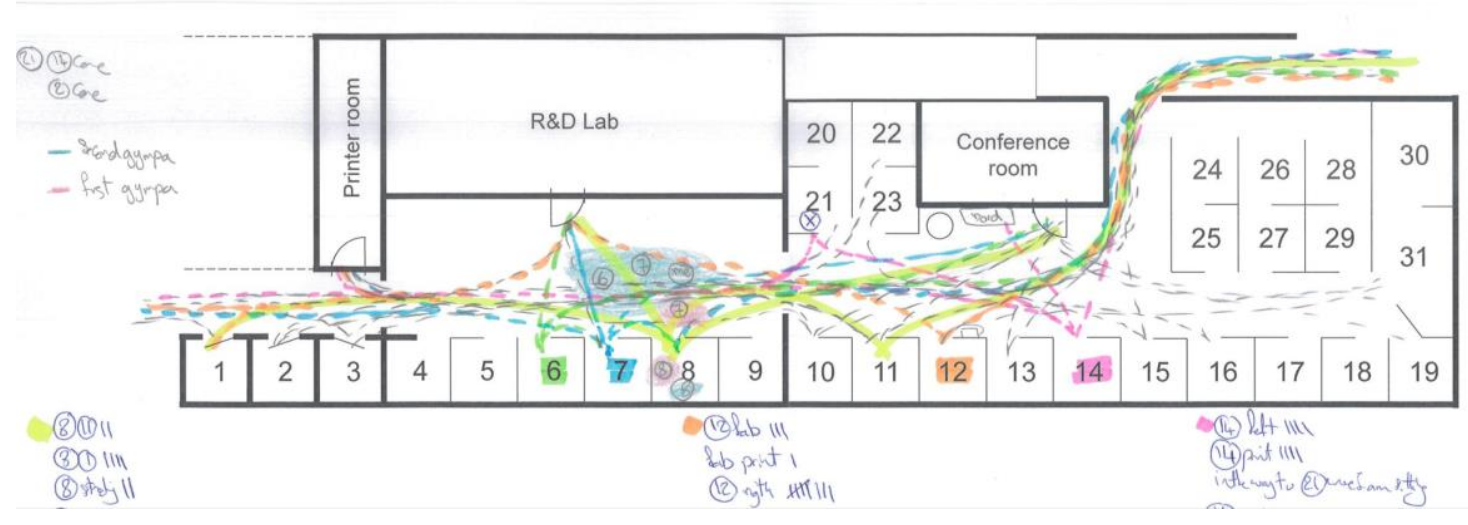

Figure 5. Local movement and mobility patterns. The space in which the exercise break was undertaken is indicated by green and purple. Spatial possibility was created within the architectural space.

NEAT-Lamps were installed on the desks of six volunteers for around 2 months. These volunteers all worked within the same space of a work environment. Initially, all the office workers of that company were informed about the dangers associated with prolonged sitting, but they were not introduced to the NEAT-Lamp prototype or the details of the study. After the presentation, six office workers volunteered to participate in the study. During this time, observational studies were conducted as the office workers interacted with the prototype. At the beginning of the study, we were interested 
to investigate how our lamp, as an additional object added to the workspace, encouraged individuals to alter their movement and mobility patterns. However, after a day, we realized that the lamp when lit illuminated the ceiling, making it visible to everyone in the environment (see Figure 6). Therefore the interaction between the office worker and the lamp was not limited to the individual, but was visible to everyone in the workspace. This light shining on the ceiling created open-ended discussions among office workers concerning their stationary habit when working on computers. As former studies also indicate, office workers would rather know about each other's identity and their activity levels in order to have discussion with one another [12]. Additionally, Lin et al. notify that office workers felt more comfortable to have discussions about their activity level with those participants that they were aware of their identity. The same also happened in our study; when we asked the participants if they wanted to withdraw from the study because of privacy matters, they all agreed to continue with the study, and no one felt that their privacy was questioned. Some office workers enjoyed the green light and ignored its message; others tried to change the current situation. In the following, we give two examples of the behavior we observed.

Observation 1: As a result of the properties inherent in this object (the lamp), many of the office workers stared to use their adjustable tables and switched between sitting and standing while working with computers. In other words, the agency of this object created an awareness of the existing opportunity already created by the organization policy.

Observation 2: In another case, one of the office workers stated that whenever two or three lamps were on, they discussed taking an exercise break. In this example, the object property not only created awareness of the organization polices, but also influenced the time for taking exercise breaks (temporal appropriation), creating a trigger for workers in the office to exercise (spatial possibility).
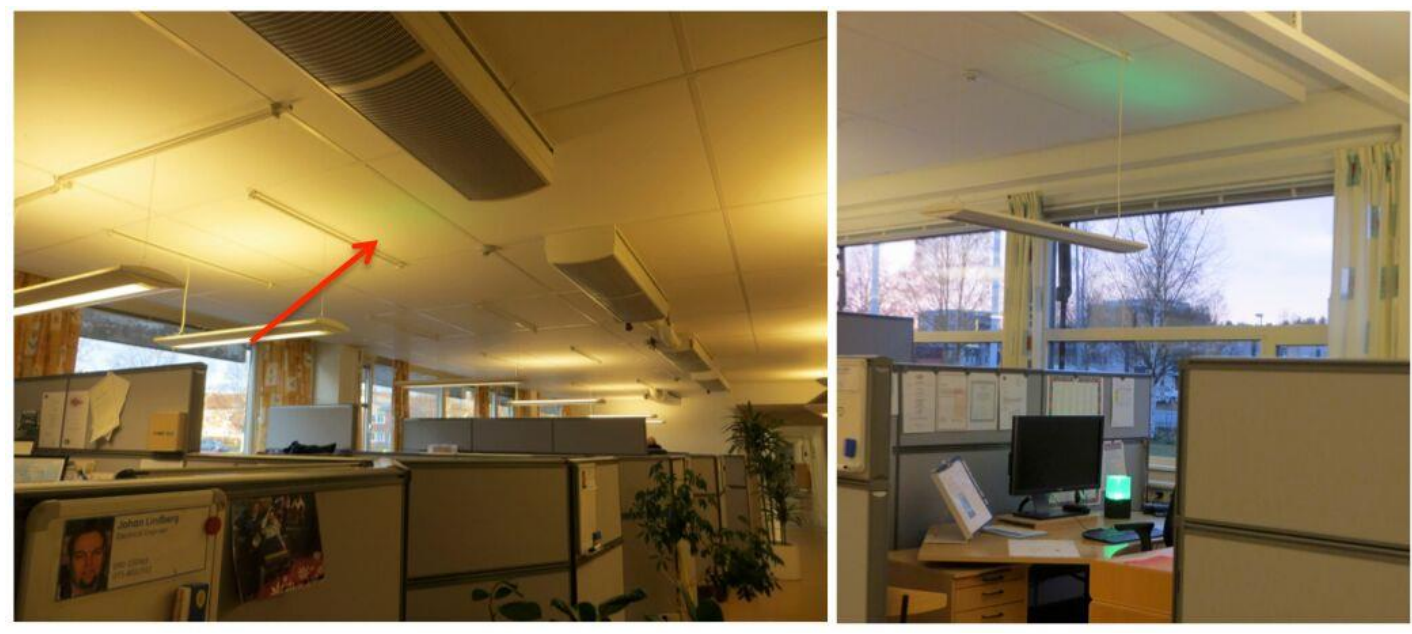

Figure 6. The light from the non-exercise activity thermogenesis (NEAT)-Lamp on the ceiling, creating open-ended discussions among office workers.

\subsubsection{Moving Forward}

As illustrated by the observations, we realized that a simple ambient lamp for reflecting PI data was not only visible to the other office workers but also triggered their curiosity. This enthusiasm was not only among those volunteer office workers that were testing the NEAT-Lamp, but also affected others in the workspace. Therefore, once again we were reminded of the importance of the social entity of workplaces when designing prototypes to foster local movement and mobility among office workers. During several brainstorming sessions, we came up with a design for a prototype that reflected not only the stationary behavior of single office workers, but mirrored the local movement and mobility patterns of all individuals in the workspace. 


\subsection{Talking Tree}

Trees have long been a symbol of wisdom in literature and stories. When designing an ambient display to reflect local movement and mobility patterns in workspaces, we tried to relate to this common narrative. Moreover, by definition, ambient displays do not function as intended if they do not properly blend with the environment [48], and thus when designing in the context of workspaces, plants are useful indigenous artifacts that we noticed during our ethnographic studies.

An effective technology for encouraging physical activity must give proper credit to the users' activities [13]. However pedometers sometimes over- or, more often, under-represent the overall level of activity. Therefore, this design avoids using quantified data representations. The Talking Tree reflects the current collective local movement and mobility level in the space.

The Talking Tree is a proximity sensor-based interactive plant that reflects the amount of local movement within a corridor by changes in the color of its leaves (see Figures 7 and 8). Sensitive colour paper was used for the leaves of this prototype. The idea behind the design of this ambient display is that, on the basis of a predefined parameter measured by a sensor, when a specified threshold is crossed, the leaves will change colour from green to white (Figures 7 and 8). The leaves of the Talking Tree are green until local movement and mobility decreases within the workspace, at which point the sensor is activated and the green colour fades to white. Thus, if there is no movement around the sensors, the Talking Tree will change colour.

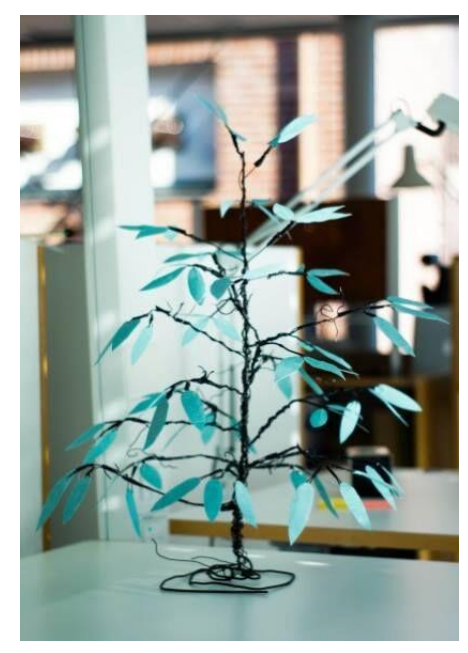

Figure 7. Talking Tree-a tree-shaped public display with interactive leaves made from sensitive colour paper.

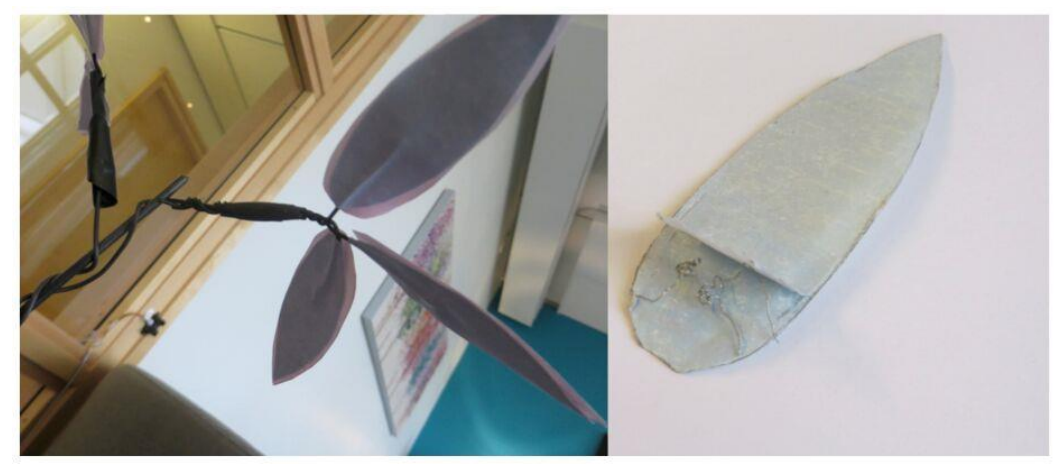

Figure 8. A close-up of a single leaf and the way a branch is wired. 


\subsubsection{Placing and Observation}

This object was placed as a pilot study in the lunchroom of the Department of Informatics (see Figure 9). The idea is to place this prototype as an artwork or a talking point in a common area such as a lunchroom. Being inspired by our previous experience of the NEAT-Lamp, this prototype was placed in a way that targeted the social entity of local movement and mobility. Therefore, lunchrooms seemed a perfect candidate in which to place this ambient display that reflects the frequency of local movement and mobility of all office workers. The sensors of the prototype, however, were placed in the main corridor of the office space to collect data from the movement of the office workers. As the Talking Tree collectively gathers data from all the office workers in the environment in an anonymous manner, thus privacy in our view is not an issue.

During this time, we faced challenges in implementing the design, some of which were solved. These challenges resulted in the replacement of the sensor and changes to the prototype. One of the initial challenges in the pilot study was the visibility of the color change in the leaves. Because of the light coming from the windows and the lamps within the lunchroom, it was hard to perceive the color change in the prototype. As a result, we decided to change the colors of the leaves to a darker color (see Figure 10).

Despite the changes ahead of the pilot testing of the Talking Tree, overall, the reaction towards the plant was very positive. The office workers in the Department of Informatics appreciated the idea and the concept of the design. Mostly, they considered the prototype from an aesthetic point of view and expressed their preference for the pink color of the leaves. Apart from the charming look of the prototype, the Talking Tree was successful in relation to our conceptual framework. During the 2 month pilot study, we heard many informal discussions related to local movement and mobility patterns among office workers.

Observation 1: In informal talks, which were sometimes humorous, office workers reflected on their spatial possibilities and discussed ways of expanding their possibilities for more movement by using other object properties. As an example, one of the office workers who had a printer in her room reflected that it might be better if she stopped using her printer and instead tried to use the printers in the printing room.

Observation 2: More office workers reflected on their organization polices, thinking of ways to improve the situation in the department by requesting adjustable tables and having walking meetings. In having walking meetings, they were investigating temporal appropriation. While some discussed these agencies for increasing their local movement and mobility, others decided to take a lunch walk with those that were close to them (social relation).

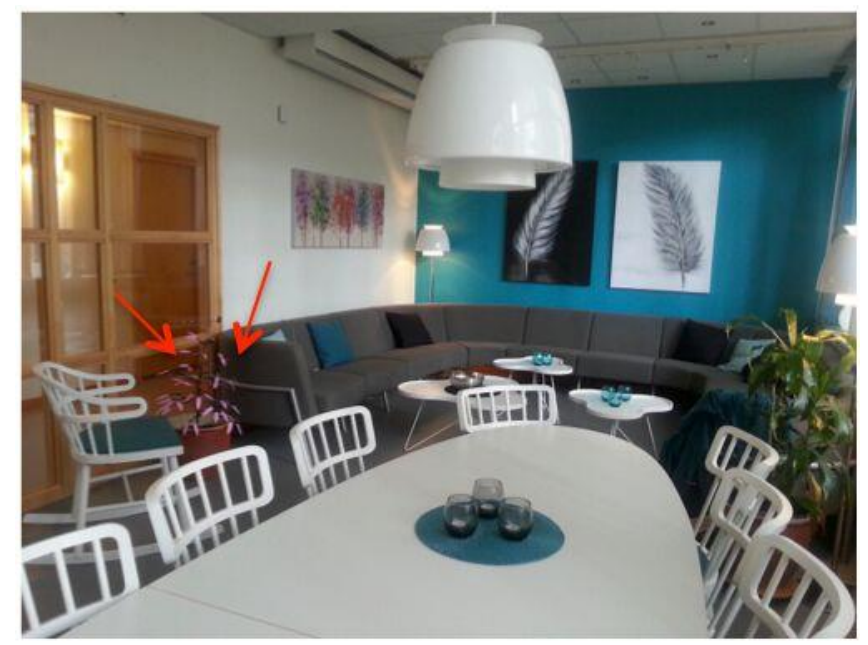

Figure 9. The setting in which the Talking Tree was tested. The lunchroom is a location in the workspace suitable for informal conversations. 


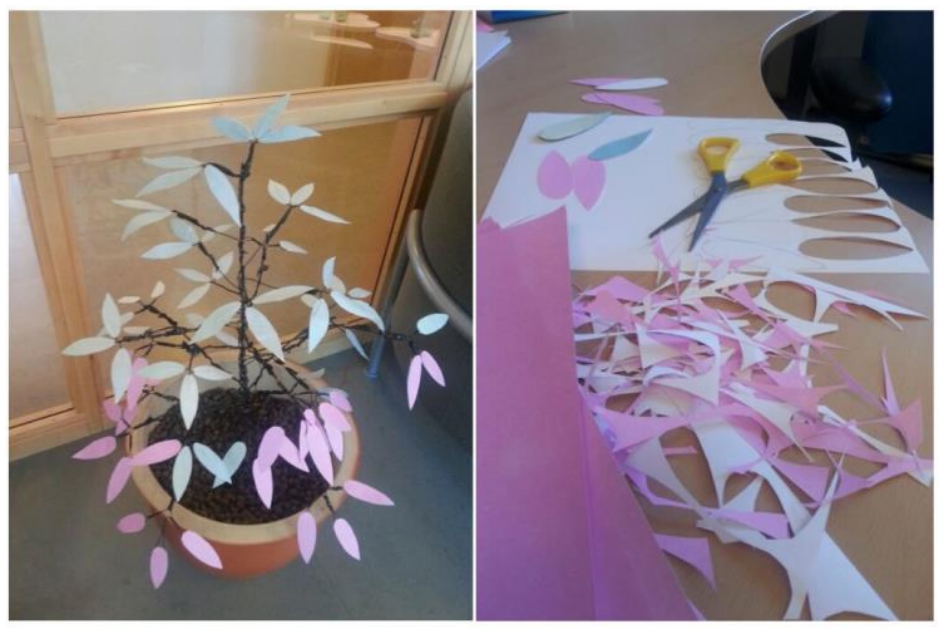

Figure 10. Changing the colors of the leaves for better visibility.

\subsubsection{Future Steps}

Although the reaction towards the Talking Tree was, as we anticipated, based on the conceptual framework of the design, this was only the early stage of developing this prototype. After debugging this design, we plan to conduct a full study of the design in an office environment. Similarly to our previous attempts, this study will also be accompanied by an observational study. Hopefully, this study will provide valuable insights to allow us to develop similar designs and our conceptual framework as the foundation for the prototypes. Finally, such feedback may result in theoretical developments regarding the design of PI systems in social settings such as office spaces in order to increase local movement and mobility.

\section{Discussion}

We hope that by presenting our conceptual framework and challenges associated with our design work, we have opened up the discussion regarding the design of PI systems for office spaces. By introducing our conceptual framework, first we wished to draw attention to existing local movements in workspaces. Being locally mobile in workspaces is an embedded practice in socially constructed workplaces (see Figures 2 and 5). Although a number of ethnographic studies have mentioned this point [30,31], designers in the field of PI and QS systems have disregarded this fact.

Moreover, we wish to point out that this socially embedded practice of local movement and mobility is shaped by five agency categories (see Figure 3). When designing PI systems that promote movement and physical activity, there should be specified sustainable link agencies. A PI system that neglects the agencies that affect movement in offices might face the risk of office workers losing interest in using the system [12]. We argue that having this conceptual framework as a driving force behind the novel designs of PI in offices can create social reflection about movement therein. This social reflection will create awareness and promote collective discussion on finding ways to break stationary habits.

We are aware that there have been many designs that have used ambient displays to create awareness of the matter of prolonged sitting and encouraging physical activity in office settings $[6,7,10,11]$. Our two prototypes also use ambient displays as a way to raise awareness of this issue. However, the ways that the NEAT-Lamp and the Talking Tree were observed and analyzed on the basis of our conceptual framework contribute to our discussion. We are not suggesting that discussion around creating opportunities to increase movement and reflecting on the current setting does not happen in association with existing PI systems, but the critical observation of such actions and discussions using the conceptual framework adds an extra dimension. These designs represent an 
entry point to designing PI systems deliberately to foster social inventions by creating open-ended discussions [1].

The benefit of such a conceptually driven design, we argue, is going beyond individual interactions and data representations. Rather than using the social aspect of using PI systems as a side-effect or as an add-on trigger [1,8], discussion and socially reflective actions become the main source of behavior change. More sustainable change can be achieved once we shed light on how socially embedded we are in our daily practices, in particular, in office environments. As noted, the social role of the affectivity in PI systems in workspaces is an unexplored topic in HCI.

We initially started with the design of the NEAT-Lamp as an individual interactive sensor-based lamp, tackling the five agencies of an individual's local movement and mobility in offices. However, this simple lamp illuminated a new path in our research in which individual interactions with the design created a reflection visible to everyone in the setting. This unanticipated outcome made a clear point to us that in order to create a change away from the stationary nature of work, all office workers should be aware and willing to play a part. Therefore, this experience led us to the design of our second prototype, the Talking Tree.

The challenges ahead of us in this project have made us reflect on our own practice [49] and think that perhaps the answer lies in the emergence of ideas behind critical design in designing PI systems. As the aim of critical design is to provide critical doubt about everyday life and its aspects, agendas and values, it could be a good starting point to reflect on the current situation. It could assist users in challenging ideologies and behavioral norms through designs that embody alternative social, cultural, technical or economic values [50]. This type of design is described as a form of social research in that the intended outcome is knowledge rather than the design of a final product addressing a specific problem. Impressively, by conducting research using the concept-driven design approach, we are exploring an end result optimized in relation to a specific idea, concept, or theory rather than a final design for a specific problem, user, or a particular use context [44], which perfectly resonates with ideas behind critical design. Therefore critical design can be characterized as an attitude rather than a method [50].

\section{Conclusions}

This paper has articulated a conceptual framework for understanding local movement and mobility within a workspace. This framework characterizes five agencies that shape movement patterns in offices and the way these could be affected. On the basis of this conceptual framework, two prototypes were designed in order to increase local movement and mobility in offices. The two designs, the NEAT-Lamp and the Talking Tree, are discussed in detail at the end of this paper.

The paper begins with a description of the motivations behind studying PI systems in office-based contexts. In doing so, it provides a review of existing PI devices and related research in this field. The paper then introduces our research from the viewpoint of a transdisciplinary research project aimed at investigating ways to increase physical activity and breaking the habit of prolonged sitting in office settings. As part of this project, two ethnographic studies lasting more than 5 months in two different offices were conducted. By characterizing the five different agencies that affect local movement and mobility in offices, this paper draws attention to the role of socially embedded practices of local mobility patterns in workspaces.

The paper then continues by introducing two design prototypes that were placed in two different office spaces. On the basis of observations, the paper describes how the prototypes created social discussion among the office workers regarding their mobility patterns during work hours. Considering the conceptual framework, the discussions resulted in expanding one or several categories of agency related to everyday movement patterns.

The paper concludes by discussing the importance of considering social elements when designing PI systems for office environments and the benefits of our proposed conceptual framework. Moreover, it continues by outlining the role of reflection in creating social awareness of local movement 
and mobility. Finally, we have suggested an alternative way of designing PI systems with the emergence of critical design, assisting users to challenge their behavior patterns and embody alternative cultures that suit their situation. Therefore, the aim of such design work would not be to create a product that immediately increases physical movement; on the contrary, the outcome would be the knowledge gained, reflections generated, and discussions among the office workers regarding their everyday movement and mobility patterns. In relation to the existing strand of research on PI design, this paper offers two contributions. First, it provides a conceptual framework in relation to agencies that shape local movement and mobility in office environments. Second, it introduces two prototypes designed for sparking collective reflections and discussions on mobility and everyday movement in offices.

Acknowledgments: This work was conducted in collaboration between the Department of Informatics, Department of Public Health and Clinical Medicine of Umeå University and the Umeå Institute of Design and was founded by the InPhAct (Increasing Physical Activity) Project. Thank you to all the InPhAct team members particularly Tommy Olsson, Viktoria Wahlström and Parag Deshpande.

Author Contributions: Fatemeh Moradi and Mikael Wiberg conceived and designed the experiments; Fatemeh Moradi performed the experiments and analyzed the data; and with the help of Mikael Wiberg they wrote the paper.

Conflicts of Interest: The authors declare no conflict of interest.

\section{References}

1. Ploderer, B.; Reitberger, W.; Oinas-Kukkonen, H.; van Gemert-Pijnen, J. Social interaction and reflection for behaviour change. Pers. Ubiquitous Comput. 2014, 18, 1667-1676. [CrossRef]

2. Swan, M. Sensor mania! The internet of things, wearable computing, objective metrics, and the quantified self 2.0. J. Sens. Actuator Netw. 2012, 1, 217-253. [CrossRef]

3. Anderson, I.; Maitland, J.; Sherwood, S.; Barkhuus, L.; Chalmers, M.; Hall, M.; Brown, B.; Muller, H. Shakra: Tracking and sharing daily activity levels with unaugmented mobile phones. Mob. Netw. Appl. 2007, 12, 185-199. [CrossRef]

4. Burns, P.; Lueg, C.; Berkovsky, S. Activmon: Encouraging physical activity through ambient social awareness. In Proceedings of the CHI'12 Extended Abstracts on Human Factors in Computing Systems, Austin, TX, USA, 5-10 May 2012.

5. Consolvo, S.; McDonald, D.W.; Toscos, T.; Chen, M.Y.; Froehlich, J.; Harrison, B.; Klasnja, P.; LaMarca, A.; LeGrand, L.; Libby, R. Activity sensing in the wild: A field trial of ubifit garden. In Proceedings of the SIGCHI Conference on Human Factors in Computing Systems, Florence, Italy, 5-10 April 2008.

6. Fan, C.; Forlizzi, J.; Dey, A.K. A spark of activity: Exploring informative art as visualization for physical activity. In Proceedings of the 2012 ACM Conference on Ubiquitous Computing, Pittsburgh, PA, USA, 5-8 September 2012.

7. Forlizzi, J.; Li, I.; Dey, A.K. Ambient Interfaces that Motivate Changes in Human Behavior. In Proceedings of the Ambient Information Systems, Toronto, ON, Canada, 13 May 2007.

8. Foster, D.; Linehan, C.; Kirman, B.; Lawson, S.; James, G. Motivating physical activity at work: Using persuasive social media for competitive step counting. In Proceedings of the 14th International Academic MindTrek Conference: Envisioning Future Media Environments, Tampere, Finland, 6-8 October 2010.

9. Geleijnse, G.; Van Halteren, A.; Diekhoff, J. Towards a mobile application to create sedentary awareness. In Proceedings of the CHI 2011: 29th ACM Conference on Human Factors in Computing Systems, Vancouver, BC, Canada, 7-12 May 2011.

10. Hazlewood, W.R.; Stolterman, E.; Connelly, K. Issues in evaluating ambient displays in the wild: Two case studies. In Proceedings of the SIGCHI Conference on Human Factors in Computing Systems, Vancouver, BC, Canada, 7-12 May 2011.

11. Jafarinaimi, N.; Forlizzi, J.; Hurst, A.; Zimmerman, J. Breakaway: An ambient display designed to change human behavior. In Proceedings of the CHI'05 Extended Abstracts on Human Factors in Computing Systems, Portland, OR, USA, 2-7 April 2005.

12. Lin, J.J.; Mamykina, L.; Lindtner, S.; Delajoux, G.; Strub, H.B. Fish'n'Steps: Encouraging physical activity with an interactive computer game. In UbiComp 2006: Ubiquitous Computing; Springer: Berlin, Germnay, 2006; pp. 261-278. 
13. Consolvo, S.; Everitt, K.; Smith, I.; Landay, J.A. Design requirements for technologies that encourage physical activity. In Proceedings of the SIGCHI Conference on Human Factors in Computing Systems, Montréal, QC, Canada, 22-27 April 2006.

14. Li, I.; Dey, A.; Forlizzi, J. A stage-based model of personal informatics systems. In Proceedings of the SIGCHI Conference on Human Factors in Computing Systems, Atlanta, GR, USA, 10-15 April 2010.

15. Pina, L.R.; Ramirez, E.; Griswold, W.G. Fitbit+: A behavior-based intervention system to reduce sedentary behavior. In Proceedings of the 6th International Conference on Pervasive Computing Technologies for Healthcare (PervasiveHealth), San Diego, CA, USA, 21-24 May 2012.

16. Pirzadeh, A.; He, L.; Stolterman, E. Personal informatics and reflection: A critical examination of the nature of reflection. In Proceedings of the CHI'13 Extended Abstracts on Human Factors in Computing Systems, Paris, France, 27 April-2 May 2013.

17. Swan, M. The quantified self: Fundamental disruption in big data science and biological discovery. Big Data 2013, 1, 85-99. [CrossRef] [PubMed]

18. Thorp, A.A.; Healy, G.N.; Winkler, E.; Clark, B.K.; Gardiner, P.A.; Owen, N.; Dunstan, D.W. Prolonged sedentary time and physical activity in workplace and non-work contexts: A cross-sectional study of office, customer service and call centre employees. Int. J. Behav. Nutr. Phys. Act. 2012, 9, 128. [CrossRef] [PubMed]

19. Cresswell, T. On the Move : Mobility in the Modern Western World; Taylor \& Francis: London, UK, 2006.

20. Barnes, R.M. Motion and Time Study Applications; Wiley: Hoboken, NJ, USA, 1953.

21. Shephard, R.J. Men at Work: Applications of Ergonomics to Performance and Design; Charles C Thomas Publisher: Springfield, IL, USA, 1974.

22. Moradi, F.; Wiberg, M. Redesigning Work-From Sedentariness to Activeness. Procedia Technol. 2013, 9, 1005-1015. [CrossRef]

23. Moradi, F. Working out Work: From Personal Informatics to Redesigning Work. Ph.D. Thesis, Umeå University, Umeå, Sweden, 2016.

24. Das, B.; Grady, R.M. Industrial workplace layout design an application of engineering anthropometry. Ergonomics 1983, 26, 433-447. [CrossRef] [PubMed]

25. Kling, R. Computerization at work. In Computerization and Controversy: Value Conflicts and Social Choices; Wiley: Hoboken, NJ, USA, 1996; Volume 2, pp. 278-308.

26. Winner, L. Playpen or Prison'. In Computerization and Controversy: Value Conflicts and Social Choices; Wiley: Hoboken, NJ, USA, 1996.

27. Corlett, E. Analysis and Evaluation of Working Posture; Butterworths: London, UK, 1983; Volume 13.

28. Barab, S.A.; Thomas, M.K.; Dodge, T.; Squire, K.; Newell, M. Critical design ethnography: Designing for change. Anthropol. Educ. Q. 2004, 35, 254-268. [CrossRef]

29. Dourish, P. Implications for design. In Proceedings of the SIGCHI Conference on Human Factors in Computing Systems, Montréal, QC, Canada, 22-27 April 2006.

30. Bellotti, V.; Bly, S. Walking away from the desktop computer: Distributed collaboration and mobility in a product design team. In Proceedings of the 1996 ACM Conference on Computer Supported Cooperative Work, Boston, MA, USA, 16-20 November 1996.

31. Luff, P.; Heath, C. Mobility in collaboration. In Proceedings of the 1998 ACM Conference on Computer Supporzted Cooperative Work, Seattle, WA, USA, 14-18 November 1998.

32. Fujiki, Y.; Kazakos, K.; Puri, C.; Buddharaju, P.; Pavlidis, I.; Levine, J. NEAT-o-Games: Blending physical activity and fun in the daily routine. Comput. Entertain. 2008, 6, 21. [CrossRef]

33. Levine, J.A. Nonexercise activity thermogenesis (NEAT): Environment and biology. Am. J. Physiol. Endocrinol. Metab. 2004, 286, E675-E685. [CrossRef] [PubMed]

34. Levine, J.A.; Schleusner, S.J.; Jensen, M.D. Energy expenditure of nonexercise activity. Am. J. Clin. Nutr. 2000, 72, 1451-1454. [PubMed]

35. McAlpine, D.A.; Manohar, C.U.; McCrady, S.K.; Hensrud, D.; Levine, J.A. An office-place stepping device to promote workplace physical activity. Br. J. Sports Med. 2007, 41, 903-907. [CrossRef] [PubMed]

36. Straker, L.; Abbott, R.A.; Heiden, M.; Mathiassen, S.E.; Toomingas, A. Sit-stand desks in call centres: Associations of use and ergonomics awareness with sedentary behavior. Appl. Ergon. 2013, 44, 517-522. [CrossRef] [PubMed]

37. Van der Ploeg, H.P.; Chey, T.; Korda, R.J.; Banks, E.; Bauman, A. Sitting time and all-cause mortality risk in 222497 Australian adults. Arch. Intern. Med. 2012, 172, 494-500. [CrossRef] [PubMed] 
38. Keim, N.L.; Blanton, C.A.; Kretsch, M.J. America's obesity epidemic: Measuring physical activity to promote an active lifestyle. J. Am. Diet. Assoc. 2004, 104, 1398-1409. [CrossRef] [PubMed]

39. Taylor, W.C.; King, K.E.; Shegog, R.; Paxton, R.J.; Evans-Hudnall, G.L.; Rempel, D.M.; Chen, V.; Yancey, A.K. Booster Breaks in the workplace: Participants' perspectives on health-promoting work breaks. Health Educ. Res. 2013, 28, 414-425. [CrossRef] [PubMed]

40. Shin, D.-H.; Biocca, F. Health experience model of personal informatics: The case of a quantified self. Comput. Hum. Behav. 2017, 69, 62-74. [CrossRef]

41. Holmquist, L.E.; Skog, T. Informative art: Information visualization in everyday environments. In Proceedings of the 1st International Conference on Computer Graphics and Interactive Techniques in Australasia and South East Asia, Melbourne, Australia, 11-14 February 2003.

42. Weiser, M.; Brown, J.S. Designing calm technology. Power Grid J. 1996, 1, 75-85.

43. Hallnäs, L.; Redström, J. Slow technology-Designing for reflection. Pers. Ubiquitous Comput. 2001, 5, $201-212$. [CrossRef]

44. Stolterman, E.; Wiberg, M. Concept-driven interaction design research. Hum. Comput. Interact. 2010, 25, 95-118. [CrossRef]

45. Höök, K.; Löwgren, J. Strong concepts: Intermediate-level knowledge in interaction design research. ACM Trans. Comput. Hum. Interact. 2012, 19, 23. [CrossRef]

46. Blomberg, J.; Karasti, H. Reflections on 25 years of ethnography in CSCW. Comput. Support. Coop. Work 2013, 22, 373-423. [CrossRef]

47. Kakihara, M.; Sørensen, C. Expanding the 'mobility' concept. ACM SIGGroup Bull. 2001, 22, 33-37. [CrossRef]

48. Ishii, H.; Wisneski, C.; Brave, S.; Dahley, A.; Gorbet, M.; Ullmer, B.; Yarin, P. ambientROOM: Integrating ambient media with architectural space. In Proceedings of the CHI 98 Cconference Summary on Human Factors in Computing Systems, Los Angeles, CA, USA, 18-23 April 1998.

49. Schön, D.A. The Reflective Practitioner: How Professionals Think in Action; Basic Books: New York, NY, USA, 1983; Volume 5126.

50. Bardzell, J.; Bardzell, S. What is critical about critical design? In Proceedings of the SIGCHI Conference on Human Factors in Computing Systems, Paris, France, 27 April-2 May 2013.

(C) 2017 by the authors. Licensee MDPI, Basel, Switzerland. This article is an open access article distributed under the terms and conditions of the Creative Commons Attribution (CC BY) license (http://creativecommons.org/licenses/by/4.0/). 